\title{
Carnap, Wittgenstein e o problema da metafísica
}

\author{
Carnap, Wittgenstein and the problem of metaphysics
}

\author{
Antonio lanni Segatto \\ antonio.iannisegatto@gmail.com \\ (Universidade Estadual Paulista, São Paulo, Brasil)
}

\begin{abstract}
Resumo: 0 artigo pretende, em primeiro lugar, caracterizar o programa de superação da metafísica proposto por Rudolf Carnap no artigo "Superação da metafísica pela análise lógica da linguagem" e apresentar um paralelo entre suas conclusões e aquelas apresentadas por Moritz Schlick em textos anteriores. Em segundo lugar, pretende-se mostrar que a filiação de Carnap ao Tractatus logico-philosophicus de Wittgenstein está baseada em uma compreensão sui generis da noção mesma de contrassenso e da tese de que as supostas proposições da metafísica são destituídas de sentido. Essa compreensão, porém, se baseia na apropriação do verificacionismo que o próprio Wittgenstein propôs no início da década de 1930.
\end{abstract}

Palavras-chave: Carnap; Wittgenstein; Schlick; metafísica; contrassenso.

\begin{abstract}
The article aims, first, to characterize the program of eliminating metaphysics proposed by Rudolf Carnap in the article "The elimination of metaphysics through logical analysis of language" and to stress the parallel between the author's conclusions and those presented by Moritz Schlick in earlier texts. Secondly, we intend to show that the affiliation of Carnap to Wittgenstein's Tractatus LogicoPhilosophicus is based on a sui generis understanding of the very notion of nonsense and the claim that the alleged metaphysical propositions are meaningless. This understanding, however, is based on the appropriation of the verificationism that Wittgenstein himself proposed in the early 1930s.
\end{abstract}

Keywords: Carnap; Wittgenstein; Schlick; metaphysics; nonsense.

Em 1931, Rudolf Carnap publicava um artigo polêmico, intitulado "Superação da metafísica pela análise lógica da linguagem", no segundo volume da revista Erkenntnis. Como observou Philipp Frank, "entre os numerosos escritos de Carnap, provavelmente nenhum teve um efeito tão grande e amplo quanto [esse] artigo" (Frank, 1963, p.158). E, segundo o antigo colega de Carnap, esse amplo efeito se manifestou por meio de reações contraditórias: por um lado, os detratores da metafísica encontraram no texto um conforto, já que sua aversão à metafísica era justificada pela lógica; por outro, os defensores da metafísica viram no artigo um ataque flagrante a certos "valores espirituais" justamente sob a perspectiva de uma 
lógica pedante. Seja como for, uma coisa parece certa. Que se tome um partido ou outro (ou nenhum deles), não se pode negar que o artigo de Carnap é um dos marcos de uma certa linhagem filosófica que une nomes tão díspares quanto os de Hume e Wittgenstein. Com efeito, ele retoma a condenação da metafísica proposta por Hume, mas o faz por uma via diversa, já que tal condenação resulta não de uma investigação do entendimento humano, mas da análise lógica da linguagem. E nesse ponto fica evidente a filiação de Carnap à chamada “nova lógica” e, em particular, ao Tractatus logico-philosophicus de Wittgenstein. ${ }^{1}$

Cumpre notar que essa confluência da condenação humeana da metafísica com o instrumental analítico fornecido pela nova lógica é um leitmotiv que define, em grande medida, a feição do chamado "positivismo lógico"2, do qual Carnap foi um dos representantes mais destacados. Na introdução ao volume que reúne alguns dos principais textos do movimento intelectual, Alfred J. Ayer nota que o último parágrafo da Investigação sobre o entendimento humano constitui uma excelente declaração da posição positivista. Como se sabe, Hume resumia sua condenação da metafísica ao dizer que se tomarmos nas mãos um volume qualquer de teologia ou metafísica não encontraremos raciocínios nem sobre relações de ideias nem sobre questões de fato, os dois tipos em que podem ser naturalmente divididos todos os objetos da razão ou investigações humanas. Restava, portanto, apenas uma alternativa: "Às chamas com ele, então, pois não pode conter senão sofismas e ilusão” (Hume, 2004, p.222). No entanto, Ayer nota também que, embora a postura geral fosse idêntica àquela de Hume, no caso do positivismo, o epíteto “lógico" foi acrescido a fim de enfatizar sua incorporação das descobertas da lógica moderna, em particular, o simbolismo desenvolvido, entre outros, por Frege e Russell. E é precisamente na confluência que promove entre a condenação humeana da metafísica e a "nova lógica" que o positivismo lógico revela sua dívida em relação a Wittgenstein:

A originalidade dos positivistas lógicos residia em fazer a impossibilidade da metafísica depender não da natureza do que pode ser conhecido, mas da natureza do que pode ser dito. Sua acusação contra o metafísico era a de que ele viola as regras que qualquer enunciado deve satisfazer para que seja literalmente significante. Desde o início, sua formulação dessas regras estava vinculada a uma concepção acerca da linguagem que Wittgenstein, o qual a herdara de Russell, tornara completamente explícita em seu

\footnotetext{
$1 \mathrm{Em}$ um texto em que apresenta os ganhos trazidos pela chamada "nova lógica", Carnap declara: "O desejo de substituir a poesia conceitual metafísica por um método de filosofar estritamente científico permaneceria um desejo piedoso se só se tivesse à disposição, enquanto ferramenta lógica, o sistema da lógica tradicional. Ela era completamente incapaz de satisfazer as exigências de riqueza conceitual, rigor formal e utilidade técnica que a nova tarefa exigia dela" (Carnap, 19301, pp.12-3). E na última seção do texto, intitulada "A eliminação da metafísica", ele declara: "Não há filosofia como teoria, como sistema de proposições próprias ao lado das proposições da ciência. Praticar filosofia significa nada mais que clarificar os conceitos e proposições da ciência pela análise lógica. 0 instrumento para isso é a nova lógica" (idem, p.26).

2 Para uma breve história do "positivismo lógico" e da origem do próprio termo, cf. Blumberg; Feigl, 1931.
} 
Tractatus (Ayer, 1959, p.11).

Essa cruzada antimetafísica pode ser retraçada a escritos anteriores de Carnap e de outros membros do "Círculo de Viena", no interior do qual surgiu o "positivismo lógico”. Com efeito, em “A virada da filosofia”, publicado no início da década de 1930, Moritz Schlick pretendia por um ponto final no conflito das filosofias e, para tanto, denunciava um dos erros mais graves cometidos no passado pela metafísica: "O esforço dos metafísicos estava dirigido ao objetivo absurdo [widersinnig] de expressar o conteúdo das qualidades puras (a 'essência' das coisas) por meio de conhecimentos, portanto, de dizer o indizível" (Schlick, 2008, p.219). E ele remetia essa tese a um texto anterior, intitulado "Vivência, conhecimento, metafísica", publicado em 1926, em que fazia uma afirmação bastante semelhante:

Essas questões [da metafísica] surgem quando se toma o que só pode ser o conteúdo de uma apreensão [Kennen] como o conteúdo possível de um conhecimento [Erkenntnis], isto é, quando se tenta comunicar o que, por princípio, não é comunicável, exprimir o que não é exprimível (Schlick, 2008a, p.36).

Em suma, a metafísica pretende conceituar aquilo que não pode ser conceituado. Ocupada com o que Carnap chamará de "sentimento vital", a metafísica dá um verniz teórico e trata como objeto de determinação conceitual o que não pode sê-lo (cf. Benoist, 2001). Aliás, antecipando em certa medida a conclusão a que chegará Carnap anos mais tarde no texto mencionado, Schlick caracterizava os "filosofemas metafísicos" como "poesias conceituais": "eles desempenham no todo da cultura um papel semelhante ao da poesia, eles contribuem ao enriquecimento da vida, não do conhecimento. Eles devem ser avaliados como obras de arte, não como verdades" (Schlick, 2008a, p.54). No entanto, o texto do início da década de 1930 anuncia uma novidade. A nova direção da filosofia dependia dos caminhos desbravados pela lógica. Embora Frege e Russell tivessem aberto trilhas importantes, teria sido Wittgenstein quem deu a virada definitiva. ${ }^{3}$ A conclusão de Schlick, aliás, guarda certas ressonâncias wittgensteinianas: "No lugar de investigações da 'capacidade humana de conhecimento', na medida em que não podem ser respondidas pela psicologia, entra a consideração sobre a essência da expressão, da representação, isto é, de qualquer 'linguagem' no sentido mais geral da palavra” (Schlick, 2008, p.216).

Carnap também registra sua recepção da nova lógica. Em sua “Autobiografia intelectual", ele relata que assistiu a alguns cursos de Frege na década de 1910 e leu atentamente os Principia Mathematica de Russell e Whitehead, leitura esta

3 Sobre a presença do pensamento de Wittgenstein na constituição do Círculo de Viena, cf. também Kraft, 1966, pp.11-25. 
que foi motivada pelas menções de Frege ao livro em seus cursos. ${ }^{4}$ Tal leitura representou, segundo o próprio autor, uma modificação importante na maneira como passaria encarar os problemas filosóficos: "Quando considerava um conceito ou uma proposição em uma discussão científica ou filosófica, eu pensava que a havia entendido claramente se achasse que podia expressá-la, se quisesse, em uma linguagem simbólica” (Carnap, 1963, p.10). Embora Frege tenha uma influência importante sobretudo no que diz respeito às suas concepções acerca da lógica e da matemática, Russell foi aquele de quem ele mais aprendeu. Segundo Carnap, as páginas finais de Nosso conhecimento do mundo exterior de Russell soaram como uma exortação pessoal. A afirmação russelliana de que "a lógica fornece o método de investigação na filosofia" foi tomada por ele como uma espécie de lema que o acompanharia por toda sua trajetória: “a aplicação do novo instrumental lógico com o propósito de analisar conceitos científicos e clarificar problemas filosóficos tem sido o objetivo principal da minha atividade filosófica" (idem, p.12). Esse propósito, aliás, já era anunciado em 1928, em Der logische Aufbau der Welt, que "pretende dar um primeiro passo nesse caminho e, com isso, permitir outros passos nessa direção" (Carnap, 1966, p.XVIII). E era justamente a passagem da nova lógica para as "questões da teoria do conhecimento" que Carnap tematizava neste contexto:

É compreensível historicamente que a nova lógica tenha encontrado interesse inicialmente apenas no domínio estrito dos matemáticos e lógicos. Sua importância notável para toda a filosofia foi pressentida apenas por poucos; sua apreciação nesses outros domínios mal começou (...) Trata-se aqui, principalmente, das questões da teoria do conhecimento, isto é, da redução de conhecimentos a outros conhecimentos. A fecundidade do novo método se mostra no fato de que a resposta à questão da redução conduz a um sistema genealógico de redução dos conceitos tratados na ciência, que exige apenas poucos conceitos de base (Carnap, 1966, p.XVIII).

Na sequência, Carnap anuncia a consequência negativa que o projeto envolvia e que será objeto de consideração em "Superação da metafísica pela análise lógica da linguagem": "A partir do momento que se tomou a sério na filosofia a exigência do rigor científico, foi preciso necessariamente banir da filosofia toda a metafísica, pois suas teses não podem ser justificadas racionalmente” (Carnap, 1966, p.XIX).

Essas considerações programáticas, tanto em sua dimensão positiva quanto em sua dimensão negativa, seriam retomadas no famoso Manifesto do "Círculo de Viena", redigido por Hans Hahn, Otto Neurath e Carnap. Os autores caracterizam a tarefa da filosofia como sendo o esclarecimento de problemas e enunciados, e o método para tanto seria a análise lógica. Não é difícil notar a ressonância wittgensteiniana presente nessa declaração geral. Embora Frege e Russell já fornecessem os meios para a realização do projeto de uma “concepção científica do mundo”, é o impacto da leitura do Tractatus, sobretudo em Carnap, que permite extrair todas as

4 As anotações de Carnap foram publicadas em Reck, Awodey, 2004. 
consequências que decorrem da realização daquela tarefa. Em uma passagem do Manifesto, que vale a pena citar na íntegra, já se delineia o percurso traçado em "Superação da metafísica pela análise lógica da linguagem":

Se alguém afirma "Deus existe", "o fundamento originário do mundo é o inconsciente", "há uma enteléquia como princípio condutor no ser vivo", não lhe dizemos: "o que você diz é falso", mas perguntamos: "o que você quer dizer com seus enunciados?". E então se mostra haver um limite preciso entre as duas espécies de enunciados. À primeira, pertencem os enunciados tais como são feitos na ciência empírica. Seu sentido se constata mediante análise lógica ou, mais exatamente, mediante redução aos enunciados mais simples sobre o que é dado empiricamente. Os outros enunciados, a que pertencem os anteriormente mencionados, mostram-se totalmente vazios de significado, caso sejam tomados como o metafísico os entende. Pode-se certamente, com frequência, transformá-los em enunciados empíricos. Neste caso, porém, perdem seu conteúdo de sentimento, que é, na maioria das vezes, precisamente essencial ao metafísico. O metafísico e o teólogo, compreendendo mal a si próprios, crêem expressar algo com suas proposições, descrever um estado de coisas. A análise mostra, todavia, que tais proposições nada significam, sendo apenas expressão de algo como um sentimento vital. Tal expressão pode ser uma tarefa significativa no âmbito da vida. 0 meio adequado a isso é, porém, a arte: a poesia lírica ou a música, por exemplo. Se, em vez disso, se escolhe a roupagem verbal de uma teoria, surge um perigo: simula-se um conteúdo teórico onde não existe nenhum. Caso o metafísico ou o teólogo queiram manter a roupagem linguística habitual, devem ter claro e reconhecer nitidamente que não realizam descrição, mas expressão, que não produzem teoria, isto é, comunicação de conhecimento, mas poesia ou mito. Se um místico afirma ter vivências que se situam sobre ou para além de todos os conceitos, não se pode contestá-lo, mas ele não pode falar sobre isso, pois falar significa apreender em conceitos, reduzir a fatos [Tatbestände] cientificamente articuláveis (Hahn; Neurath; Carnap, 1986, pp.10-1 (trad. modificada)).

Aparentemente, há uma concordância em relação às tarefas que Wittgenstein colocava para a filosofia. Com efeito, é possível distinguir duas atividades complementares que o Tractatus prescreve a toda filosofia futura: a análise lógica das proposições com sentido e a crítica lógica das ilusões e contrassensos da filosofia tradicional. Essa crítica lógica fica encarregada de mostrar que a filosofia, em sua tentativa de conhecer os fundamentos absolutos do mundo, é necessariamente conduzida a ilusões e contrassensos. O mesmo parece ocorrer no caso de Carnap: a denúncia da falta de sentido das supostas proposições da metafísica não seria senão a contrapartida da idéia de que proposições com sentido podem ser submetidas a uma análise completa. No entanto, sob um olhar mais detido, as distâncias que separam Carnap e Wittgenstein ficam evidentes. Para este último, a análise completa das supostas proposições metafísicas não chega a termo, pois se trata de uma combinação ilegítima de sinais, que não chega a constituir um símbolo, uma combinação de sinais em que não foi conferido significado a um ou mais de seus elementos. Não é esse, porém, o diagnóstico de Carnap. Como veremos, embora declare sua filiação ao Tractatus, as razões pelas quais ele decreta a falta de sentido 
das supostas proposições da metafísica são distintas. A discussão desse descompasso pode esclarecer aspectos importantes das relações entre Carnap e Wittgenstein.

A certa altura de "Superação da metafísica pela análise lógica da linguagem", Carnap insere uma nota de rodapé a fim de indicar ao leitor qual é a "concepção lógica e epistemológica" que dá sustentação às teses defendidas no artigo. A esse propósito, ele menciona seu Der logische Aufbau der Welt e o Tractatus de Wittgenstein, bem como uma obra de Waismann, ainda em preparação naquele momento, que deveria resultar das conversas que este último mantivera com Wittgenstein no início da década de $1930 .{ }^{5}$ Como se viu, o artigo retoma algumas teses que já haviam sido apresentadas tanto no Aufbau quanto no Manifesto. E, como também se viu, fica claro na leitura de ambos que Wittgenstein desempenha um papel fundamental não apenas no que diz respeito à formulação dos problemas, mas também no que diz respeito à sua solução, ou melhor, à sua dissolução. Com efeito, tudo indica que são os aforismos 4.111 e 4.112 do Tractatus que são retomados no final do Manifesto quando os autores escrevem que a "nova concepção científica do mundo" se opõe à filosofia tradicional na medida em que nela “não se estabelecem 'proposições filosóficas' próprias, mas apenas se esclarecem proposições, e precisamente as proposições da ciência empírica" e que "não há filosofia como ciência fundamental ou universal, ao lado ou sobre os domínios da ciência empírica” (Hahn; Neurath; Carnap, 1986, p.18). Além disso, cumpre lembrar que Carnap encerrava o Aufbau citando os aforismos 6.5 e 6.52 do Tractatus, assim como a sentença do Prefácio segundo a qual "o que se pode em geral dizer, pode-se dizer claramente; e sobre aquilo de que não se pode falar, deve-se calar", passagem que era precedida pelo comentário de que o livro era "valioso por suas consequências lógicas, assim como pela postura ética que dele resulta” (Carnap, 1966, p.261).

Essa filiação a Wittgenstein, aliás, é reiterada por Carnap em sua “Autobiografia

\footnotetext{
5 Essa obra, que seria intitulada Lógica, linguagem, filosofia, ficou inacabada e permaneceu inédita até 1965. David Stern resume os percalços da colaboração entre Wittgenstein e Wasimann nos seguintes termos: "O trabalho de Waismann no livro pode ser dividido em várias fases distintas. Durante a primeira fase, do final dos anos vinte até 1931, ele planejava escrever uma introdução abrangente à filosofia de Wittgenstein, incorporando as principais ideias do Tractatus e o trabalho mais recente de Wittgenstein numa exposição sistemática. Em 1930, o volume planejado, Lógica, Linguagem, Filosofia, foi anunciado na Erkenntnis, como o primeiro volume de uma série de livros expondo as visões do Círculo de Viena. Contudo, Wittgenstein tornou-se cada vez mais descontente com o plano, escrevendo para Schlick, em 20 de novembro de 1931, que ele estava "convencido de que Waismann apresentaria muitas coisas em uma forma completamente diferente da que considero ser correta". As coisas chegaram ao seu ápice em 9 de dezembro, quando Wittgenstein encontrouse com Waismann para discutir as "Teses", um sumário da interpretação por Waismann de sua filosofia. De modo característico, Wittgenstein repudiou não apenas os detalhes da exposição de Waismann, mas até mesmo o título, insistindo que nada em sua filosofia consistia na formulação de teses. É essa discordância ou equívoco fundamental que se tornou o maior obstáculo à tentativa de Wittgenstein de colaborar com Waismann em uma exposição sistemática de suas ideias, mesmo se tratando apenas de reescrever o que Wittgenstein disse, ou de organizar o que Wittgenstein ditou a Waismann, pois isto ainda fracassava em capturar o que Wittgenstein estava tentando expressar com estas ideias". (Stern, 2009, p.66).
} 
intelectual". Ele lembra que boa parte do Tractatus foi lida e discutida, frase a frase, nos encontros do Círculo. Segundo seu relato, uma idéia influente de Wittgenstein era justamente aquela que se tornaria a tese fundamental do artigo:

[Uma] idéia influente de Wittgenstein é concepção de que muitas proposições filosóficas, especialmente na metafísica, são pseudoproposições, destituídas de conteúdo cognitivo. Eu descobri que a visão de Wittgenstein sobre esse ponto era próxima àquela que eu desenvolvera anteriormente sob a influência de cientistas e filósofos antimetafísicos. Eu me dei conta de que muitas dessas proposições e questões se originam de um mau uso da linguagem e de uma violação da lógica. Sob a influência de Wittgenstein, essa concepção se fortaleceu e se tornou mais precisa e radical (Carnap, 1963, p.24).

No entanto, embora Carnap reconheça expressamente a influência de Wittgenstein, sabe-se que as relações entre este último e o Círculo de Viena são bastante complexas e controvertidas. Sabe-se que Wittgenstein manteve encontros regulares com membros do Círculo entre o final da década de 1920 e o início da década de 1930. Sabe-se também que os membros do Círculo reconheceram expressamente sua dívida em relação a Wittgenstein. No entanto, ele nunca se reconheceu inteiramente na produção daqueles. É conhecido o episódio que culminou no rompimento entre Carnap e Wittgenstein. No início de maio de 1932, ele recebeu uma separata do artigo “A linguagem fisicalista como linguagem universal da ciência” (Carnap, 1931), que marca o distanciamento de Carnap em relação às análises fenomenalistas da linguagem científica. Em 6 de maio de 1932, ele escreve a Schlick manifestando a preocupação de que seu próprio trabalho fosse visto posteriormente como não mais do que "uma versão requentada ou como plágio do trabalho de Carnap":

Vejo-me levado contra a minha vontade para dentro do que é chamado "o Círculo de Viena". Nesse Círculo, prevalece a propriedade comum, de tal modo que eu poderia, por exemplo, usar as ideias de Carnap se eu quisesse, mas ele também poderia usar as minhas. Mas eu não quero me juntar a Carnap e pertencer a um círculo ao qual ele pertence. Se eu tenho uma macieira em meu jardim, então me delicia e serve ao propósito dessa árvore se meus amigos (por exemplo, você e Waismann) pegarem as maçãs; eu não afugentarei ladrões que pularem a cerca, mas estou no direito de me indignar com o fato de eles fingirem ser meus amigos ou alegarem que a árvore pertence a eles conjuntamente (Apud Stern, 2009, p.73).

Embora se refira à apropriação indevida de suas ideias no artigo referido, não seria exagero dizer que Wittgenstein se indignaria igualmente com a apropriação sui generis que Carnap faz da idéia de que as supostas proposições da metafísica são destituídas de sentido, bem como a apropriação sui generis de algumas teses e noções fundamentais do Tractatus. Como observa Peter Hacker, em sua empreitada de superação da metafísica, ele se apropriou de algumas ideias ou teses do livro, mas rejeitou outras (cf. Hacker, 2001, pp.333-4). E essa postura ambivalente revela sua compreensão peculiar da noção de contrassenso presente no livro, assim como do 
próprio projeto filosófico em causa ali. Carnap aceita as teses de que toda necessidade é necessidade lógica e de que as proposições da lógica são tautologias, isto é, proposições sem-sentido [sinnlos], mas ele rejeita a idéia de que as proposições da lógica representam a armação do mundo e a idéia de que a lógica é uma imagem especular do mundo, enfim, a idéia de que a lógica é transcendental (cf. Wittgenstein, 1994, 6.124 e 6.13). Além disso, Carnap aceita a idéia de que não há proposições filosóficas, mas apenas elucidações filosóficas de proposições não-filosóficas e, com isso, a idéia de que proposições filosóficas são destituídas de sentido. No entanto, ele não admite a idéia de que a metafísica é inefável, a idéia de que há "verdades" metafísicas que são mostradas pela linguagem, mas que não podem ser proferidas. Apesar da aparente concordância entre ambos e da referência expressa de Carnap ao Tractatus, as razões pelas quais ele rejeita a metafísica são distintas das razões pelas quais Wittgenstein a rejeita. $E$ isso se deve, mais especificamente, à sua apropriação sui generis da noção mesma de contrassenso presente no livro. Antes de nos determos nesse ponto, convém retomar brevemente alguns pressupostos tractarianos.

As proposições da lógica e as chamadas proposições filosóficas não satisfazem, segundo o Tractatus, a condição de sentido mais fundamental, a saber: a bipolaridade. No entanto, ainda que a conclusão seja a mesma em ambos os casos, as razões para tanto são diferentes. Se as proposições da lógica resultam de uma combinação legítima de sinais, mesmo que tal combinação, em função das operações envolvidas, constitua um caso-limite de proposicionalidade, as chamadas proposições filosóficas resultam de uma combinação ilegítima de sinais, que não chega a constituir um símbolo. Isso porque não foi conferido significado a um ou mais de seus elementos, porque ao menos uma de suas partes não realiza uma possibilidade sintática e, assim, o sinal proposicional não chega a simbolizar, não chega a estabelecer relações projetivas com um estado de coisas. Se no primeiro caso a combinação de sinais beira a dissolução desta mesma combinação, no segundo caso, sequer há algo que possa ser reconhecido como uma proposição. Daí a distinção crucial entre proposição sem-sentido [sinnlos] e contrassenso [Unsinn].

As únicas proposições com sentido dizem respeito à existência ou inexistência de estados de coisas contingentes. As proposições da lógica, embora sintaticamente bem construídas, não têm sentido, pois não representam nada e são, no final das contas, analíticas. As supostas proposições filosóficas, por sua vez, estão aquém da sintaxe lógica da linguagem. Disso resulta que toda proposição com sentido é sintética a posteriori e diz respeito única e exclusivamente ao que é contingente, ao que é o caso, mas poderia, em princípio, não ser.

Tanto as confusões presentes na linguagem comum quanto as confusões filosóficas são excluídas pela sintaxe lógica da linguagem. Uma notação que obedeça à gramática lógica, diz Wittgenstein, deve excluir combinações que empregam o 
mesmo sinal para símbolos diferentes (cf. Wittgenstein, 1994, 3.325). Ela exclui, por exemplo, aquelas combinações de sinais que pretendem falar sobre si mesmas, como ocorre na teoria dos tipos de Russell. ${ }^{6}$ Mas Wittgenstein nota também que uma notação conforme à sintaxe lógica mostra, por exemplo, que o verbo "é” pode ocorrer como cópula, como sinal de igualdade e como expressão de existência (cf. idem, 3.323), ou que palavras como “objeto”, “complexo”, “fato”, "função”, "número" designam conceitos formais e são representadas em uma "conceitografia" por variáveis: “onde quer que ela [a palavra “objeto"] seja usada de outra maneira, como um termo conceitual propriamente dito, portanto, surgem pseudoproposições, contrassensos" (idem, 4.1272). Uma notação que obedeça à sintaxe lógica, portanto, mostrará que as pseudoproposições da metafísica empregam conceitos formais como se fossem conceitos genuínos.

A aparente perplexidade causada pela conclusão do Tractatus, segundo a qual suas próprias proposições são contrassensos, se desfaz se lembrarmos que tais "proposições" devem ser lidas como os degraus da escada que conduz à solução de todos os problemas filosóficos. Na verdade, trata-se de dissolver os supostos problemas filosóficos ao mostrar que eles são falsos problemas, ao menos na forma como a filosofia tradicional os coloca. O que resta é a indicação ao leitor de que deve procurar por si mesmo aquilo que não pode ser dito por meio de proposições. Aliás, Wittgenstein dizia no Prefácio que o livro talvez só fosse entendido por quem já tivesse pensado por si mesmo o que nele é expresso. A fim de justificar esse movimento argumentativo, Peter Hacker alega ser necessário fazer algumas distinções suplementares àquelas introduzidas pelo autor. Diferentemente das proposições semsentido [sinnlos], os contrassensos violam as regras da sintaxe lógica da linguagem. Mas nem sempre essa violação acontece de maneira patente. Ela pode ocorrer de maneira manifesta, como na "questão de saber se o bem é mais ou menos idêntico ao belo" (Wittgenstein, 1994, p.4.003); mas pode ocorrer de maneira encoberta, como acontece na maioria das proposições filosóficas. Neste caso, seria possível distinguir entre contrassensos enganadores [misleading nonsense] e contrassensos esclarecedores [illuminating nonsense]. São os últimos que "irão guiar o leitor atento a apreender o que é mostrado por outras proposições que não pretendem passar por filosóficas; mais do que isso, eles irão indicar sua própria ilegitimidade àqueles que captam o que se quer dizer" (Hacker, 1986, pp.18-9). Ao fim e ao cabo, “eles nos

\footnotetext{
6 A esse respeito, Wittgenstein escreve: "Nenhuma proposição pode enunciar algo sobre si mesma, pois o sinal proposicional não pode estar contido em si mesmo (isso é toda a "Theory of Types"). Uma função não pode ser seu próprio argumento, porque o sinal da função já contém o protótipo de seu argumento e ele não pode conter a si próprio. Suponhamos, pois, que a função $F(f x)$ pudesse ser seu próprio argumento; haveria, nesse caso, uma proposição ' $F(F(f x)$ )', e nela a função externa $F$ e a função interna $F$ devem ter significados diferentes, pois a interna tem a forma $\varnothing(f x)$, a externa, a forma $\psi(\varnothing(f x))$. Ambas as funções têm em comum apenas a letra ' $F$ ', que sozinha, porém, não designa nada" (cf. Wittgenstein, 1994, 3.332-3.333).
} 
levam a ver o mundo corretamente, de um ponto de vista lógico correto" (idem, p.26). Embora o leitor deva reconhecer essas proposições como contrassensos e deva jogar a escada fora depois de ter subido por ela, ele ainda tem a posse de algumas "verdades inefáveis".

Acerca da noção de contrassenso, deve-se reconhecer que o próprio Wittgenstein diz nas aulas compiladas por Alice Ambrose que "a palavra 'contrassenso' é usada para excluir certas coisas, e por diferentes razões" (Wittgenstein, 2001, p.64). Ainda que se sustente uma concepção monista acerca do contrassenso (cf. Conant, 2001), deve-se reconhecer que certas proposições destituídas de sentido delimitam o âmbito do que pode ser dito. Uma cadeia de palavras pode não ter sentido por diferentes razões, seja porque é um mero som inarticulado seja porque expressa as próprias condições de sentido de toda e qualquer proposição legítima. Hacker reconhece que se há alguma diferença entre contrassensos não se trata de uma diferença de tipos ou graus. ${ }^{7} 0$ que diferencia as proposições filosóficas e, em particular, as proposições do Tractatus, do contrassenso puro e simples é que elas são uma tentativa de dizer o que não pode ser dito e, precisamente por essa razão, são esclarecedoras (cf. Hacker, 2001, p.117). Como nota Jacques Bouveresse, "ele nunca voltou atrás na idéia de que as proposições que exprimem necessidades conceituais não têm realmente sentido, pois não têm negação com sentido" (Bouveresse, 1991, p.93). As proposições ou pseudoproposições que exprimem as condições de sentido de toda representação proposicional estão, por essa razão, aquém da marca essencial da representação proposicional: a bipolaridade.

Em "Superação da metafísica pela análise lógica da linguagem”, Carnap cita algumas passagens do artigo “O que é metafísica?” de Heidegger como exemplo da "doutrina metafísica que exerce atualmente a maior influência na Alemanha". É curioso notar que ele poderia citar as próprias proposições do Tractatus, mas não o faz. Foi apenas posteriormente, em The logical syntax of language, que ele considerou proposições que empregam termos similares àqueles que ocorrem no Tractatus. Segundo Carnap, muitas obscuridades filosóficas resultam do uso do que ele chama de modo material de fala ao invés de um modo formal:

O hábito de formular no modo material de fala nos leva, em primeiro lugar, a nos enganarmos sobre os objetos de nossa própria investigação: sentenças pseudo-objeto nos levam a pensar que estamos lidando com objetos extra-linguísticos, tais como números, coisas, propriedades, experiências, estados de coisas, espaço, tempo,

\footnotetext{
7 A esse respeito, Hacker escreve: “Elas [as proposições do Tractatus] são contrassensos, e não são melhores logicamente que qualquer outro contrassenso, pois não há tipos logicamente diferentes ou graus de contrassenso. Mas elas são, entretanto, diferentes de mera baboseira como "Ab sur ah" pela intenção com que são proferidas, pelas expressões que ocorrem nelas e pelo papel que desempenham. Elas são proferidas na tentativa de dizer algo que não pode ser dito, mas que só pode ser mostrado. Elas contêm expressões que são usadas em outros lugares como conceitos formais. E elas são os degraus essenciais da escada por meio da qual de pode subir para atingir um ponto de vista lógico correto" (Hacker, 2001, p.332).
} 
e assim por diante; e o fato de que, na realidade, trata-se de uma questão de linguagem e suas conexões (tais como expressões numéricas, designações de coisas, coordenadas espaciais etc.) nos é encoberto pelo modo material de fala. Esse fato só se torna claro pela tradução no modo formal de fala ou, em outras palavras, em sentenças sintáticas sobre a linguagem e expressões linguísticas. Além disso, o uso do modo material de fala gera obscuridade pelo emprego de conceitos absolutos no lugar de conceitos sintáticos, que são relativos à linguagem (Carnap, 1971, pp.298-9).

No entanto, do ponto de vista de Wittgenstein, a tradução do modo material no modo formal não mudaria muita coisa. As sentenças resultantes da tradução continuariam a estar aquém da bipolaridade. Aliás, encontramos no Tractatus tais "traduções": em 1.1 , lemos "o mundo é a totalidade dos fatos, não das coisas" e, em 4.11, lemos que "A totalidade das proposições verdadeiras é toda a ciência natural (ou a totalidade das ciências naturais)", em 2.01, lemos que "O estado de coisas é uma ligação de objetos" e, em 4.22, lemos que "A proposição elementar consiste em nomes. É uma vinculação, um encadeamento de nomes". No entanto, todas essas proposições têm exatamente o mesmo estatuto. As “traduções" não são menos "essencialistas", já que elas especificam aspectos essenciais, e não contingentes, da ciência e das proposições (cf. Hacker, 2001, p.335).

O contrassenso, incluindo aí as supostas proposições da metafísica, resulta, segundo o Tractatus, da falta de determinação do sentido e não do choque entre os significados das palavras. Sua falta de sentido se deve ao fato de que ele está aquém da bipolaridade. Não é isso, porém, o que Carnap diz em "Superação da metafísica pela análise lógica da linguagem”. Segundo o artigo, há dois tipos de pseudoproposições: aquelas em que uma ou mais palavras são destituídas de significado e aquelas em que palavras com significado são combinadas de tal modo que não resulta nenhum sentido. Tanto em um caso como no outro vale a tese de que "o significado de uma palavra é determinado por seu critério (dito de outro modo: pelas relações de dedução de sua proposição elementar, por suas condições de verdade, pelo método de sua verificação)" (Carnap, 1931a, p. 223). O critério, portanto, já não é a bipolaridade, mas, em última instância, o “método de verificação". Não há, porém, uma oposição estrita entre o critério da bipolaridade e o da verificação. Em sentido literal, “verificação” é sinônimo de “tornar verdadeiro” [verum facere], como nota Balthazar Barbosa Filho; nesse sentido, portanto, Wittgenstein poderia ser chamado de "verificacionista semântico" (cf. Barbosa Filho, 2013, pp.165-6). Ao dizer que "entender uma proposição significa saber o que é o caso se ela for verdadeira” (Wittgenstein, 1994, 4.024), ele assinala a relação interna entre o fato de uma proposição ter sentido e a bipolaridade, mas não determina que se deva tomar tal relação em termos epistemológicos. Foi apenas Schlick quem estabeleceu a equação entre determinar o sentido de uma proposição e determinar como ela pode ser verificada ou falsificada. Carnap também encontra em Wittgenstein o critério de 
verificação. ${ }^{8}$ Sabe-se, diga-se de passagem, que Wittgenstein foi, ainda que por um curto período, um verificacionista convicto e que as origens desse verificacionismo podem ser retraças ao Tractatus. Se o verificacionismo wittgensteiniano do início da década de 1930 está vinculado a considerações epistemológicas que respondem a tensões presentes no Tractatus, não é exagerado afirmar que a apropriação sui generis que Carnap faz da noção mesma de contrassenso, fundada na adoção do verificacionismo como critério de sentido, não é inteiramente anti-wittgensteiniana (cf. Barbosa Filho, 1989).

Da compreensão peculiar acerca da noção mesma de contrassenso do Tractatus resulta uma compreensão peculiar acerca da concepção do que são os problemas filosóficos e qual deve ser sua solução. É certo que os problemas filosóficos são destituídos de sentido, que eles são falsos problemas e que uma clarificação da linguagem basta para fazê-los desparecer. No entanto, as razões que conduzem a essa conclusão são diferentes nos casos de Wittgenstein e Carnap. O primeiro manterá sempre a concepção, expressa nas Investigações filosóficas, de que é preciso "passar de um contrassenso velado a um contrassenso manifesto" (Wittgenstein, 2001a, §464). Carnap, diferentemente, não compreende a denúncia daquela falta de sentido como uma passagem (de um contrassenso a outro), mas como uma justaposição (do sentido ao contrassenso). Por outro lado, Carnap compreende os problemas e pseudoproposições da metafísica como resultado de uma falta de talento artístico e, em última instância, como algo que cabe aos psicólogos explicar (cf. Carnap, 1971, $\$ 80$ e também Gandon, 2001). Wittgenstein, ao contrário, compreende os problemas e pseudoproposições da filosofia como o resultado de nos lançarmos contra os limites da linguagem a fim de expressar algo que diz respeito a algo mais do que um mero "sentimento vital". Não por acaso, em uma das conversas que manteve com membros do "Círculo de Viena", ele declara compreender o que Heidegger queria dizer quando falava de "ser" e "angústia":

Eu consigo certamente ter uma noção do que Heidegger quer dizer com ser e angústia.

8 Em sua "Autobiografia Intelectual", Carnap declara a proveniência wittgensteiniana do "princípio de verificação" e a vincula à idéia de que as supostas proposições da metafísica são destituídas de sentido: "O avanço mais decisivo em minha concepção acerca da metafísica ocorreu depois [do Logische Aufbau der Welt], no período de Viena, principalmente sob a influência de Wittgenstein. Eu cheguei a sustentar a concepção segundo a qual muitas teses da metafísica tradicional não são apenas inúteis, mas inclusive destituídas de conteúdo cognitivo. Elas são pseudoproposições, isto é, elas parecem faze afirmações porque elas têm a forma gramatical de enunciados declarativos, e as palavras que ocorrem nelas contêm muitas associações fortes e carregadas emocionalmente, enquanto, na verdade, elas não fazem afirmações, não expressem proposições e não são, portanto, nem verdadeiras nem falsas (...) A concepção de que esses enunciados e questões são não-cognitivos estava baseada no princípio de verificação de Wittgenstein. Esse princípio diz, primeiramente, que o sentido de um enunciado é dado pelas condições de sua verificação e, em seguida, que um enunciado é dotado de sentido se e apenas se é, em princípio, verificável, isto é, se há circunstâncias possíveis, não necessariamente atuais, que, se ocorrerem, estabeleceriam definitivamente a verdade do enunciado"(Carnap, 1963, pp.44-5). 
O homem tem o impulso de se lançar contra os limites da linguagem (...) Esse lançarse contra os limites da linguagem é o ético. Eu considero muito importante que se ponha fim nessa conversa fiada sobre a ética - se há um conhecimento, se há valores, se o bem pode ser definido (...) Mas a tendência, o lançar-se indica algo (Wittgenstein, 1984, pp.68-9).

Apenas anos mais tarde, na mencionada “Autobiografia intelectual”, Carnap reconhecerá a "diferença impressionante" entre a atitude de Wittgenstein em relação aos problemas filosóficos e aquela de Schilck e dele próprio. Não por acaso, ele remeterá tal diferença a um conflito interno de Wittgenstein:

Seu intelecto, trabalhando com grande intensidade e poder de penetração, reconheceu que muitos enunciados no campo da religião e da metafísica, estritamente falando, não dizem nada. Em sua característica honestidade absoluta consigo mesmo, ele não tentou fechar seus olhos para essa idéia. Mas esse resultado era extremamente doloroso para ele emocionalmente, como se ele fosse compelido a admitir uma fraqueza de uma pessoa amada. Schlick e eu, diferentemente, não tínhamos amor pela metafísica ou pela teologia metafísica e, portanto, podíamos abandoná-las sem conflito interno ou arrependimento. Antes, quando estávamos lendo o livro de Wittgenstein no Círculo, eu acreditei erroneamente que sua atitude em relação à metafísica era similar à nossa. Eu não dei atenção suficiente aos enunciados no livro sobre o místico, porque seus sentimentos e pensamentos nessa área eram muito divergentes dos meus. Apenas o contato pessoal com ele me ajudou a ver com mais clareza sua atitude sobre esse ponto. Eu tive a impressão que sua ambivalência em relação à metafísica era apenas um aspecto específico de um conflito interno mais básico em sua personalidade com o qual ele sofria profundamente e dolorosamente (Carnap, 1963, p.25).

Ainda que faça o mea culpa, ainda que admita não ter dado a devida atenção aos aforismos finais do Tractatus, Carnap em nenhum momento admite o teor do que é dito em tais aforismos. Em certo sentido próximo a Kant, Wittgenstein promove uma reabilitação dos objetos das metafísicas especiais (Deus, a alma imortal, o mundo como totalidade), ainda que condene a metafísica enquanto doutrina. Aquilo de que tratam as metafísicas especiais não pode ser dito, isto é, representado proposicionalmente, mas nem por isso é destituído de valor. No momento em que "Superação da metafísica pela análise lógica da linguagem" foi publicado, o próprio Wittgenstein já estava se distanciando consideravelmente do Tractatus, denunciando, entre outras coisas, o que havia de dogmático no livro, mas isso o levará a caminhos que distanciarão ainda mais de Carnap.

\section{Referências}

Ayer, A. J. (1959). “Editor's introduction”. In: A. J. Ayer (ed.). Logical positivism. New York: The Free Press.

Barbosa Filho, B. (2013). "Sobre o positivismo de Wittgenstein". In: Tempo, verdade e ação: estudos de lógica e ontologia. São Paulo: Discurso Editorial; Editora Paulus. 
Benoist, J. (2001). Schlick et la métaphysique. Les études philosophiques, 3(58), pp.301-316.

Blumberg, A. E.; Feigl, H. (1931). Logical positivism: a new movement in European philosophy. The Journal of Philosophy, 28(11), pp.281-296.

Bouveresse, J. (1991). “Wittgenstein et la philosophie du langage”. In: Herméneutique et linguistique. Combas: Éditions de l'Éclat.

Carnap, R. (1930-1). “Die alte um die neue Logik”. Erkenntnis, 1. Band.

(1931). “Die physikalische Sprache als Universalsprache der Wissenschaft”. Erkenntnis, 2. Band.

(1931a). “Überwindung der Metaphysik durch logische Analyse der Sprache”. Erkenntnis, 2. Band.

- (1963). "Intellectual Autobiography”. In: P. A. Schilpp (ed.). The philosophy of Rudolf Carnap. La Salle: Open Court.

- (1966). Die logische Aufbau der Welt. Hamburg: Felix Meiner.

(1971). The logical syntax of language. London: Routledge \& Kegan

Paul.

Conant, J. (2001). "Two conceptions of the Überwindung der Metaphysik: Carnap and early Wittgenstein”. In: T. McCarthy; S. C. Stidd (ed.). Wittgenstein in America. Oxford: Clarendon Press.

Frank, P. (1963). “The pragmatic components in Carnap's “Elimination of metaphysics””. In: P. A. Schilpp (ed.). The philosophy of Rudolf Carnap. La Salle: Open Court.

Gandon, S. (2001). "Les origines russelliennes du concept de problème philosophique chez Wittgenstein”. In: C. Chauviré; S. Laugier; J.-J. Rosat (ed.). Wittgenstein: les mots de l'esprit. Paris: J. Vrin.

Hacker, P. M. S. (1986). Insight and illusion: themes in the philosophy of Wittgenstein - revised edition. Oxford: Clarendon Press.

\section{Press.}

(2001). Wittgenstein: connections and controversies. Oxford: Clarendon

Hahn, H.; Neurath, O.; Carnap, R. (1986). A concepção científica do mundo: o Círculo de Viena. Tradução de F. P. A. Fleck. Cadernos de História e Filosofia da Ciência, 10, pp.5-20.

Hume, D. (2004). Investigações sobre o entendimento humano e sobre os princípios da moral. São Paulo: Editora UNESP.

Kraft, V. (1966). El Círculo de Viena. Madrid: Taurus.

Reck, E. H.; Awodey, S. (ed.). (2004). Frege's lectures on logic: Carnap's students notes (1910-1914). Chicago: Open Court.

Schlick, M. (2008). "Die Wende der Philosophie”. In: Die Wiener Zeit: Aufsätze, Beiträge, Rezensionen (1926-1936). Wien: Pringer Verlag. (2008a). “Erleben, Erkennen, Metaphysik”. In: Die Wiener Zeit: Aufsätze, Beiträge, Rezensionen (1926-1936). Wien: Pringer Verlag. 
Stern, D. (2009). Das Observações filosóficas à Unidade da Ciência. Dois pontos, 6(1), pp.63-95.

Wittgenstein, L. (1984). Wittgenstein und der Wiener Kreis (Werkausgabe 3). Frankfurt am Main: Suhrkamp.

. (1984a). Philosophische Grammatik (Werkausgabe Band 4). Frankfurt am Main: Suhrkamp.

. (1994). Tractatus logico-philosophicus. São Paulo: Edusp.

- (2001). Wittgenstein's lectures, Cambridge, 1932-1935: from the notes of Alice Ambrose and Margaret Macdonald. A. Ambrose (ed.). New York: Prometheus Books. (2001a). Philosophische Untersuchungen - kritisch-genetische Edition. J. Schulte (Hrsg). Frankfurt am Main: Suhrkamp.

Wrigley, M. (1989). The origins of Wittgenstein's verificacionism. Synthese, 78(3), pp.265-290. 